\title{
Intravenous Thrombolytic Therapy in Acute Stroke: Problems and Solutions
}

\section{Akut İnme Tedavisinde İntravenöz Trombolitik Tedavi: Sorunlar ve Çözümler}

M. Akif Topçuoğlu¹, E. Murat Arsava1 ${ }^{1}$, A. Özcan Özdemir², Erdem Gürkaş3, Dilek Necioğlu Örken ${ }^{4}$, Şerefnur Öztürk ${ }^{5}$

${ }^{1}$ Hacettepe University Faculty of Medicine, Department of Neurology, Ankara, Turkey

2Osmangazi University Faculty of Medicine, Department of Neurology, Eskisehir, Turkey

${ }^{3}$ Gulhane Training and Research Hospital, Clinic of Neurology, Ankara, Turkey

${ }^{4}$ Istanbul Bilim University Faculty of Medicine, Department of Neurology, Istanbul, Turkey

5 Selcuk University Faculty of Medicine, Department of Neurology, Konya, Turkey

\begin{abstract}
Use of intravenous tissue plasminogen activator (tPA) is one of the key elements of acute ischemic stroke management. Its use has not become widespread, and has faced significant problems in our country for more than a quarter of a century most probably due to many unanswered questions about issues related with daily practice. However, recent developments, which adequately focused and found solutions for most of these problems and questions, have led to a major change of point of view and understanding of the hyperacute management of stroke. This article, in the light of the relevant literature, discusses and provides clear recommendations for questions directed by neurologists practicing in Turkey mainly about typical neurologic issues faced in the setting of tPA use for acute stroke.
\end{abstract}

Keywords: Stroke, thrombectomy, contraindication, avoidance, training

Öz

Akut iskemik inme tedavisinin kritik elementlerinin başında gelen intravenöz doku plazminojen aktivatörü (tPA) kullanımının yirmi yılı aşkın süre içinde ülkemizde yeterince yaygınlaşamamasının başta gelen nedenlerinden biri, kullanımına dair birçok sorunun yanıtsız kalmasıdır. Ancak, son gelişmeler ile bu soruların pek çoğuna yeterli açıklamanın getirilebilmiş olması önemli bir anlayış değişikliğine yol açmaktadır. Bu makalede akut inmede tPA tedavisi ile ilgili uzmanlarımızın yönelttiği birincil olarak nörolojik sorulara ilişkin yanıt ve açıklamalar mevcut literatür ışığında etraflıca ele alınmış ve herbiri için net tavsiyelerde bulunulmuştur.

Anahtar Kelimeler: Strok, trombektomi, kontrendikasyon, kaçınma, eğitim

\section{Introduction}

Intravenous (IV) tissue plasminogen activator (tPA), which has convincing evidence in the treatment of acute ischemic stroke, could not be used widely as desired despite the fact that it has been used for a quarter of a century. In the United Kingdom, IV tPA could only be used in $15 \%$ of patients, constituting $12 \%$ of all patients with stroke who had a chance to benefit from IV tPA in 2013 (1). In the United States of America (USA), IV tPA could not be used in $25 \%$ of patients with acute ischemic stroke who were admitted within 2 hours of the beginning of symptoms and who had no contraindications (2). In the USA, IV tPA could be used in only $3.5 \%$ of all patients with acute ischemic stroke in 2008 (3). We do not know the exact situation in Turkey, but IV tPA is

Address for Correspondence/Yazışma Adresi: M. Akif Topçuoğlu MD, Hacettepe University Faculty of Medicine, Department of Neurology, Ankara, Turkey Phone: +90 5365753634 E-mail: mat@hacettepe.edu.tr ORCID ID: orcid.org/0000-0002-7267-1431

Received/Geliş Tarihi: 21.08.2017 Accepted/Kabul Tarihi: 20.10.2017

${ }^{\circ}$ Copyright 2017 by Turkish Neurological Society

Turkish Journal of Neurology published by Galenos Publishing House. 
not widely used and much work should be done to increase the awareness of it in Turkey $(4,5)$.

The reasons for the failure of using IV tPA in the treatment of acute ischemic stroke are sophisticated. The most important reasons are the followings: the evaluation of indications for tPA in patients with acute ischemic stroke is complicated; the therapeutic window of the treatment is narrow ( 4.5 hours); and the evaluation of the clinical, imaging, and laboratory contraindications of tPA in a patient with acute ischemic stroke is complicated (Table 1). In fact, all these criteria are reflections of the criteria of inclusion and exclusion in the National Institutes of Neurological Disorders and Stroke (NINDS) Alteplase ${ }^{\circledR}$ trial for clinical practice, which was published in 1995 (6). In addition to these criteria, contraindications were added from the literature of cardiology, hematology, and basic sciences (7). Interestingly, the exclusion criteria of the European Cooperative Acute Stroke Study-1 (ECASS-1) $(8,9,10)$, which resulted negatively, were also included and the list of contraindications for IV tPA grew. The evaluation of the criteria against time and the decision-making process require training and expertise. All these conditions created the scenario in which IV tPA could only be asministered by neurologists, which also constitutes a factor for failure in the use IV tPA in the treatment of acute ischemic stroke.

The reasons for the low usage rates of IV tPA differ between countries (11). In countries including Turkey that do not have stroke centers functioning $24 / 7$ and a referral-triage-treatment system, the most important reasons are related with structural/ logistical factors. However, these are not the reasons in European countries, which have established the system, and have maintained it successfully for years (1). The perception of physicians about IV tPA is at the forefront in these countries (1). The rules and regulations in national user manuals or prospectuses, which are not based on current scientific knowledge, are important factors. In most countries, there are differences and controversies between the licensing criteria of IV tPA and the results of trials, which could affect clinical practice (12). This observation can also be applied for our country. The main purpose of this review is to exhibit these controversies on the basis of scientific data and provide a basis to our colleagues in the field. In these reviews, questions and answers about the use of IV tPA that were sent to the working group of the Turkish Neurology Society are presented. This review is the first of these reviews and includes primary neurologic problems that we encounter during the IV tPA process.

\section{Question: What should be known about the pharmacology of tPA?}

Answer: tPA is a serine protease that is synthesized by endothelial cells and is settled in the endothelial membrane. It catalyzes the transformation of plasminogen to plasmin. Plasmin degrades fibrin, which results in an intravascular fibrinolytic (thrombolytic) effect. Also, there is an in vivo tPA-plasmin system. tPA shows 1000 times or more affinity to fibrin-bound plasminogen and has "fibrin selective" and a "local" thrombolytic effect different from urokinase. Developed with recombinant DNA technology, tPA is used systematically in many thrombotic/ thromboembolic events.
Table 1. IV tPA indications

Absolute exclusion criterion: IV tPA is not given.

If treatment cannot be started within 4.5 hours after symptom onset

Any type of acute (intracerebral, subarachnoid, subdural)

hemorrhage in imaging modality

Demarcated and wide hypodensity in CT

Systolic blood pressure $>185 \mathrm{mmHg}$ or diastolic blood pressure $>110 \mathrm{mmHg}$

Thrombocytopenia $<100.000 / \mathrm{mm}^{3}$

INR $>1.7$

aPTT $>40 \mathrm{sec}$

Relative (in some cases/conditions) exclusion criterion, but most patients are appropriate for IV tPA. IV tPA may be given.

The onset time could not be determined

Detected stroke at wake

Cranial/spinal surgery within the last 3 months

Cranial/spinal trauma within the last 3 months

Ischemic stroke within the last 3 months

Gastrointestinal hemorrhage within the last 3 weeks

Genitourinary hemorrhage within the last 3 weeks

Major surgery within the last 3 weeks

Major systemic trauma within the last 2 weeks

Puncture to the arteries that cannot be compressed within the last 1 week History of intracranial hemorrhage

The use of NOACs (non-vitamin K antagonist oral anticoagulants) (last 48 hours)

End-stage renal failure, dialysis

Severe liver failure, Cirrhosis

Aortic dissection

Infective endocarditis

Systemic malignancy

Intracranial intra-axial tumor or mass

Intracranial AVM

Diffuse Anterior ST elevation myocardial Infarction (STEMI)

Pericarditis

Dural puncture within the last 7 days

Not an exclusion criterion. IV tPA may be given.

Hyperdense artery sign in CT

Minor stroke (NIHSS <5)

Major stroke (NIHSS $>22$ )

Quickly recovering patient

Incidental intracranial aneurysm

Extra-axial intracranial tumor

Cervicocranial arterial dissection

Advanced age ( $>80$ years)

Dementia

Epileptic seizure

Disability that does not prevent mobility before stroke

Hyperglycemia

Hypoglycemia

Menstrual bleeding

Pregnancy

Acute myocardial infarction (non-STEMI, posterior or inferior STEMI)

Intracardiac thrombus

Use of aspirin and/or clopidogrel within the last 7 days

IV heparin use (last 24 hours, aPTT <40 sec)

Low molecular weight heparin use (last 24 hours, aPTT $<40$

seconds, anti-factor Xa normal)

IV: Intravenous, tPA: Tissue plasminogen activator, CT: Computed tomography, INR: International normalized ratio, aPTT: Activated partial thromboplastin time, AVM: Arteriovenous malformation, NIHSS: The National Institutes of Health Stroke Scale 
Discovered by Astrup in 1947, tPA is a glycopeptide that weighs $68 \mathrm{kDA}$ and contains 527-530 amino acids. The carbohydrate rate is 13 . tPA in circulation is rapidly inactivated by plasminogen activator inhibitor-1 (PAI-1). In healthy subjects, the serum tPA antigen level (the inactive form that makes a complex with PAI-1) is $5 \mu \mathrm{g} / \mathrm{L}$ and tPA activity (the active form, which is not bound) is $1 \mu \mathrm{g} / \mathrm{L}$. Increased serum tPA antigen and PAI1 levels are frequently seen in diabetes mellitus and are accepted as cardiovascular risk biomarkers. A slightly lower response to systemic tPA in patients with diabetes mellitus and stroke is thought to be related with increased serum tPA antigen and PAI-1 levels. The tPA-PAI-1 complex level reaches its highest level in the morning and steadily falls during the day. This situation is accounted for by the diurnal variation of stroke.

tPA in circulation is rapidly cleared by the liver. The plasma half-life of free tPA is approximately 4 minutes. If the PAI- 1 level is high, the half-life of free tPA decreases to 3 minutes or lower. The plasma half-life of tPA-PAI-1 complex is approximately 2 minutes. Five minutes after the cessation of tPA infusion, $50 \%$ of tPA in circulation is cleared, and after 10 minutes, $80 \%$ is cleared. However, the effects of tPA on hematologic parameters [more or less extending international normalized ratio (INR), extending activated partial thromboplastin time (aPTT), decreasing fibrinogen level] last hours. Its metabolites are excreted by the kidneys.

Vials of tPA $(10,20$, and $50 \mathrm{mg})$ should only be mixed with sterile water given with a vial (the concentration becomes $1 \mathrm{mg} / \mathrm{cc}$ ). It should never be shaken/foamed. It should not be mixed with other liquids and it should be given through a separate vein. It should be given within 8 hours following preparation.

The dose regimen of tPA in stroke is $0.9 \mathrm{mg} / \mathrm{kg}$. The upper limit of the dose is $90 \mathrm{mg}$. Ten percent of the total dose is given as a bolus and the rest is infused in 1 hour.

\section{Question: Is there an upper limit of The National Institutes of Health Stroke Scale (NIHSS) for IV tPA?}

Answer: There is no upper limit of NIHSS for IV tPA. In the user manual that is valid in Turkey, it is recommended that tPA should be avoided in severe stroke, which is defined clinically as having NIHSS $>25$ or having appropriate radiologic imaging features.

The NINDS trial showed that IV tPA was more effective in patients with moderate stroke. However, IV tPA is superior to placebo in patients with NIHSS $>20$. In this trial, when age and clinic severity were evaluated together, no age-NIHSS threshold could be detected, which is related with the ineffectiveness or higher harm- lower benefit (6). Other data have been added over time to support the first consideration. IV tPA was related with better outcomes compared with the control group in the VISTA (13) (1.57 times) and STTCG (14) (3.25 times) trials, and IV tPA was found to be beneficial in every trial. As expected, the level of effectiveness of IV tPA was lower in patients with severe stroke compared with patients with mild stroke. Only $7.1 \%$ of 309 patients $(7.1 \%$ vs. $2.6 \%)$ with NIHSS $>22$ fully recovered, whereas $11.6 \%$ (control $8.2 \%$ ) of the patients with NIHSS 16-21 and $24.9 \%$ (control $21.7 \%$ ) of the patients with NIHSS 11-15 fully recovered in the STTCG trial (14). A meta-analysis involving randomized and controlled trials of IV tPA showed that only $9 \%$ of patients ( $n=622$ ) had NIHSS $\geq 22$ (14). In these patients, the rate of excellent outcomes (mRS 0-1) at 3 months was $0.5 \%$ in the tPA group, and was $0.3 \%$ in the control group. At 3 months, IV tPA decreased the rate of patients with mRS 0-2 by $1 \%$ [95\% confidence interval (CI): $-2.3-4.1 \%$ ] and patients with mRS 5-6 by $0.6 \%$ (95\% CI: $-2-4.1 \%$ ). The mortality rate at 3 months was $46.2 \%$ in the tPA group, and was $44.1 \%$ in the control group. These findings show that the efficacy of the treatment does not disappear but becomes obvious with increasing clinical scores $(14,15)$ and the scientific basis of treating patients with NIHSS $>20$ with IV tPA is satisfactory. As a result, there is a need for revision in the user manual.

In the original United States Food and Drug Administration (FDA) approval, treating patients with NIHSS >22 was not contraindicated but it was advised to treat these patients "with caution". This warning originated from the fact that higher NIHSS is related with higher bleeding rates (6). However, it should be noted that the increase in the bleeding rate is not enough for us not to treat these patients.

\section{Question: Are patients with very mild stroke treated with IV tPA?}

Answer: Yes, IV tPA is effective in mild stroke. Avoiding treatment of patients with NIHSS $<5$ to prevent potential risks was excluded from the last FDA's user manual (16). The 2013 American Heart Association/American Stroke Association (AHA/ASA) guideline recommends treating every patient with a measurable neurologic deficit with IV tPA (7), which was also recommended in the original NINDS trial (6). In the "methods" part of the NINDS trial, minor stroke was defined as stroke only causing sensorial or ataxia symptoms or stroke presenting with isolated motor deficit of one extremity that results in scoring 1 point in NIHSS. However, there were only 58 patients with NIHSS $<5$ in this trial. Approximately 3000 patients were not randomized because of having mild deficit or rapid clinic improvement (17). It is not possible to draw conclusions about treating patients with mild stroke with IV tPA from the NINDS trial, but post hoc analyses could show that IV tPA is effective in patients with NIHSS $0-1$ who score 0 points in the first part of NIHSS, in patients who are categorized as having small vessel disease, and in patients with motor and sensorial deficit without a cortical symptom (18).

Having symptoms suggestive of minor stroke is accepted as an exclusion criterion in the guidelines of some countries (19). In our guidelines, "a rapid improvement in stroke symptoms before starting infusion, or having only mild symptoms" is written under "in patients with acute ischemic stroke, in addition to others, IV tPA should not be given in the following conditions (20)." No detail was given but it was thought to be identical to the FDA's "not having a measurable deficit" criterion. Patients who score 0 points in NIHSS and patients with no functional loss can be followed up without giving IV tPA.

In a meta-analysis of randomized controlled trials of IV tPA in stroke, 666 patients with NIHSS $\leq 4$ constituted $10 \%$ of all patients (14). In the tPA group, the rate of excellent outcomes 
(mRS 0 or 1 ) at 3 months was $8 \%$ higher (CI: 4.5-11.1\%) compared with the control group. The rate of patients with mRS 0-1 was $34.6 \%$ and $26.8 \%$ in the tPA and the control groups, respectively. The rate of patients with mRS $0-2$ was $66.9 \%$ and $58.9 \%$ in the tPA and control groups, respectively. The mortality rate was $0.2 \%$ higher in the tPA group compared with the control group, which was not statistically significant $(2.4 \%$ vs. $2.2 \%)$. However, the rate of patients with mRS 5-6 was $0.1 \%$ lower in the tPA group compared with the control group. This meta-analysis clearly shows that patients with mild stroke already have good outcomes, but better outcomes can be achieved with IV tPA. Symptomatic bleeding was reported in 6 of 345 patients in the tPA group and in 1 of 321 patients in the control group. These findings show that IV tPA is safe in this population of patients.

An important point to remember is that patients with low initial NIHSS do not have good outcomes as it is thought. Of the patients with NIHSS $<5$ initially, 30\% could not walk without help at discharge and $29 \%$ were discharged from hospital to a rehabilitation center (21). Excluding motor deficit (monoparesis), aphasia, and hemianopsia; cognitive dysfunction, exhaustion, depression, and decline in motor skills, which are not covered by NIHSS, contribute to poor outcomes. Also, worsening of initial mild deficit or recurrence when IV tPA is avoided are not rare. Patients with mild deficit and large vessel occlusion are at risk in terms of clinical worsening. IV tPA should be administered and thrombectomy should be planned in such patients (16).

Question: Can IV tPA be administered to patients who show partial improvement before starting IV tPA?

Answer: Yes, IV tPA should be administered to patients who show partial improvement. In the first FDA's packet note, IV tPA was not advised in patients who show "rapid" and "significant" improvement because the risk/benefit ratio of IV tPA was not well known. However, this warning was removed with revisions published in subsequent years. In the ASA/AHA guideline, the term "patients with measurable deficit should be treated with IV tPA" does not entirely involve patients who improve rapidly and significantly but still have considerable deficit and these patients are left in the "relatively excluded category" (7). However, when definitions and explanations were revised, the necessity of administering IV tPA to almost all of these patients appears. Rapid and significant improvement was used as a criterion to exclude patients with transient ischemic attack (TIA) in the original NINDS trial. In another words, IV tPA was administered to all patients except those who improved rapidly and became symptom-free or had mild symptoms. Rapid improvement is the most commonly used (29-43\%) criterion for exclusion. Dramatic improvement is defined as a decrease in NIHSS by 8-15 (mean 10) points. Whether the remaining deficit is important is the issue in this case. This issue was investigated by "The Re-Examining Acute Eligibility for Thrombolysis" (TREAT) (22) group and important deficit was defined as homonim hemianopsia ( 2 points from the third item of NIHSS), aphasia (2 or 3 points from the $9^{\text {th }}$ item of NIHSS), visual or sensorial suppression phenomenon (any point from the $11^{\text {th }}$ item of NIHSS), marked motor deficit (2 or more points from the 6 and/or $7^{\text {th }}$ items of NIHSS), and NIHSS $>5$.
Also, the opinion of the treating neurologist should be considered, and in this context, swallowing, articulation, and hand functions are considered as having critical importance. Accordingly, a dramatic decrease in NIHSS could still leave an important deficit and IV tPA should be administered in such patients.

Question: If the patient's symptoms improved fully during tPA infusion, what should we do then?

Answer: Rarely, during tPA infusion, does neurologic deficit fully improve. In this case, infusion should be completed. In such patients, NIHSS is lower (mean 5 points), age is younger, frequency of diabetes mellitus and cardioembolism are lower (23). In 24 hours following IV tPA, dramatic improvement is observed in $25 \%$ of patients $(24,25)$. Although it has many definitions, at least a $50 \%$ decrease in NIHSS and reduction of NIHSS below 4 points are commonly used definitions for dramatic improvement (24). In half of such patients, which constitute $10-15 \%$ of all patients given IV tPA, full improvement is achieved (25). If there is no diffusion restriction in diffusion-weighted images, these patients are defined as having "aborted stroke" not "TIA" (25). To define a patient as having "aborted stroke", occlusion should be revealed through vascular imaging before lytic treatment. Strokemimics constitute $10 \%$ of patients who improve fully (25).

\section{Question: Can IV tPA be administered to patients who have prior ischemic infarction?}

Answer: These patients should be considered individually based on the size of the lesion and severity of the neurologic deficit, but in most patients IV tPA can be administered and having prior ischemic stroke is not a definite contraindication.

Un-updated user manuals and guidelines accept "having ischemic stroke in last 3 months" as an exclusion criterion (7). This criterion was removed from the new FDA prescription guidelines (26). "Not having an ischemic stroke in last 3 months" was directly taken from the "tPA usage in acute myocardial infarction (AMI)" guideline and put into NINDS's criteria (16). There are not enough data in the literature to make a decision about this topic.

If a patient is admitted with stroke recurrence in the first 3 months following discharge, IV tPA causes a mild increase in the bleeding rate. In the Safe Implementation of Treatments in StrokeEast Registry (SITS-EAST), the trial which has the highest number of patients, 5594 patients were included between 2003-2010. IV tPA-related bleeding was found higher although not statistically significant in $146(2.7 \%)$ patients who had ischemic stroke in the last 3 months $[\mathrm{OR}=1.84 ; 95 \% \mathrm{CI}:(0.64-5.32)]$. On the other hand, IV tPA was found to be associated with less good functional outcomes and survival rates in patients with ischemic stroke in the last 3 months, which could be due to the accumulative effect of strokes (12).

There are many patients reported in the literature who worsened following IV tPA. In some, the first deficit worsened following a partial improvement, and in others a new attack with different symptoms occurred. The rate of early recurrent ischemic stroke (ERIS) in hospital is $0.6-2.6 \%$ (27). The cause of ERIS could not be clearly shown in many patients. Theoretically, embolism caused 
by dissolution of intracardiac, valvular, aortic or intravascular fresh thrombus is suggested as a mechanism in some case reports (28). Mechanical thrombectomy is commonly performed in such patients. Some patients are reported in the literature to have died because of bleeding (at least one patient) besides good results (at least 13 patients) $(29,30,31,32)$ being documented in patients with ERIS following IV tPA. In this context, the time interval inbetween and localization, volume, and nature of the infarction are important factors for decision-making.

In this context, patients with TIA constitute a special group. IV tPA can be administered in patients with stroke following TIA. If stroke occurs 72 hours after TIA, then IV tPA should be administered beyond doubt (33). In a case series consisting of 22 patients who were administered IV tPA within 24 hours following TIA, an increase in symptomatic bleeding (3.5\% vs. $13.8 \%$ ) was reported, but also mortality and good clinical outcome rates were reported unchanged (34). In a case series of 23 patients who were administered IV tPA within an average of 9 hours following TIA, no difference in terms of bleeding rates (8.6\%) was reported (35). In another case series, no bleeding was reported in patients who were administered IV tPA in the first day following TIA among 25 patients (36). As a result, there is a tendency of decrease in risk as time passes and in terms of early recurrence following TIA, IV tPA is equally safe and more effective. It is necessary to evaluate patients from this perspective. The reason for better clinical outcomes in these patients is earlier administration of IV tPA in hospital.

As a result, in some patients who had an ischemic stroke in the last 3 months, IV tPA can be administered in term of recurrence of ischemic stroke (37). IV tPA can be avoided if ischemic stroke recurs in patients who have prior large infarction and severe disability. However, in patients with a small subacute infarction and without any other contraindication, IV tPA can be considered safely and effectively. Such patients should be evaluated individually based on the volume, localization, and severity of disability of prior and possible new lesions (12). The intervening time is not a decisive factor.

Question: Can IV tPA be administered in patients who have previously been treated with IV tPA if stroke recurs?

Answer: Administering IV tPA in such patients is indicated and beneficial according to case reports in the literature (37). Antibody development and allergic adverse events with repeated uses are expected with streptokinase but they are not with tPA. Therefore, positive or negative results are the same with first-time use and second- or third-time use of IV tPA for stroke. For example, in one of the largest series, of 22 patients who were treated with IV tPA for the second time after 3 hours-2280 days, 16 had good outcomes at 3 months and 2 had an asymptomatic intracerebral hemorrhage. In this series, 5 of 9 patients with stroke recurrence in the last 3 months had good outcomes (30).

How soon IV tPA can be administered safely for the second time in a patient who was treated with IV tPA is an uncommon but important problem. IV tPA-induced "early fibrin degradation coagulopathy" improves in 36 hours and administering IV tPA for the second time after 36 hours is thought to be safe (38). However, aPTT, INR, D-dimer, and fibrinogen levels should be checked in the first 36 hours to exclude systemic fibrinolysis. The increase in INR following IV tPA peaks in 3-6 hours and INR levels reach $1.1-2$ in $10 \%$ of patients and exceeds 2 in $1.5 \%$ of patients (39). In this case, standard thresholds (INR $<1.7$, aPTT $<40$, D-dimer $<2$ $\mathrm{nmg} / \mathrm{mL}$, fibrinogen $>100 \mathrm{mg} / \mathrm{dL}$ ) for IV tPA can be used.

\section{Question: Can IV tPA be administered in patients with prior hemorrhagic stroke?}

Answer: IV tPA is contraindicated in patients with prior intracranial hemorrhage in guidelines and user manuals of the FDA, AHA, and Turkey $(7,20,26)$. Intracranial hemorrhage involves all spontaneous and traumatic hemorrhages including intraparenchymal, intracerebral, subarachnoid, and subdural hemorrhages. The FDA changed this criterion in the last product label as "recent" intracranial hemorrhage. However, no details were given about this change (16). More patients who had prior intracranial hemorrhage without bleeding were reported in the literature compared with patients with bleeding following IV tPA. No bleeding was reported in at least 2 patients who had subarachnoid hemorrhage (SAH) and did not undergo surgery $(40,41)$. However, the low number of patients prevents us from drawing conclusions. In general, IV tPA is not recommended in intracranial hemorrhage causing encephalomalasia (16). Otherwise, IV tPA can be used.

Question: Can IV tPA be administered to patients with cerebral microhemorrhage $(\mathrm{CMH})$ ?

Answer: Due to the lack of data, treating patients with $\mathrm{CMH}$ under magnetic resonance imaging (MRI) is controversial. Balancing potential risks and benefits is required, but there is no measurement that can be used for this. $\mathrm{CMH}$ is found in $15-35 \%$ of patients in whom IV tPA will be administered, which means it is not rare (42). Having $\mathrm{CMH}$ causes 2.5 times more symptomatic intracerebral hemorrhage risk following IV tPA (43). However, this statistically significant risk increase was not shown in other studies (44).

There may be a relation between post-IV tPA symptomatic intracerebral hemorrhage risk and number and locations of $\mathrm{CMH}$. As the number of CMHs increases, bleeding risk increases too, but a clear threshold has not been shown (45). In a meta-analysis, 12.1 times more symptomatic bleeding [95\% CI: (4.36-33.6)] was reported to be related with 10 or more CMHs (43). In another meta-analysis, 2.3 times more symptomatic bleeding was reported to be related with 5 or more CMHs (46). Finally, another metaanalysis showed that bleeding risk rises 1.9 times per $\mathrm{CMH}$ (47). However, it was shown that the risk did not rise in relation with the number of CMHs in some studies (42).

On the other hand, basal (hypertensive)-type and corticosubcortical (amyloid angiopathy)-type $\mathrm{CMH}$ localizations could change the risk of bleeding. Cortical siderosis and parieto-occipital cortical microhemorrhages could be related with higher bleeding risk. In short, IV tPA can be avoided in patients with many and amyloid-type CMHs. Although $\mathrm{CMH}$ causes a mild increase in bleeding rates, to make general and clear decisions, the efficacy of IV tPA in patients with $\mathrm{CMH}$ should be evaluated in randomized and controlled studies. There is an important point: the presence 
of $\mathrm{CMH}$ decreases the rate of good outcomes in patients both with and without bleeding following IV tPA $(42,44,45)$. This could be related with small vessel dysfunction and insufficient control of risk factors.

Question: Is it possible to treat patients with IV tPA who have a clinical picture suggestive of $\mathrm{SAH}$ with normal cranial computed tomography (CT) in the emergency room?

Answer: Suspicion of SAH is an exclusion criterion for IV tPA in the original FDA user manual and in the guidelines of the AHA, but not in Turkey's user manual. It is clear that if SAH is documented in cranial CT, then IV tPA will be contraindicated. However, it has not been well studied when a patient has a suddenonset and severe headache with focal neurologic deficit suggestive of SAH, but cranial CT is normal. In this context, lumbar puncture will be inappropriate when IV tPA is administered; therefore, to exclude reversible cerebral vasoconstriction syndrome, dural sinus thrombosis, dissection, sentinel hemorrhage, and similar situations, CT angiography and cranial MRI can be used, and after exclusion of the above, IV tPA can be administered (16).

\section{Question: Can IV tPA be administered to patients with severe ischemic white matter disease?}

Answer: Yes, such patients benefit from IV tPA. Bleeding risk following IV tPA increases 2-fold when there is severe white matter disease (Fazekas grade 3) in the initial cranial CT (48). In a metaanalysis including 15 studies and 6957 patients, a 1.65-fold increase (additional 2.5\% risk) in symptomatic intracerebral hemorrhage risk was found associated with the presence of leukoaraiosis. If leukoaraiosis is moderate/severe (Fazekas 2 and 3), the increase in risk will be 2.4 times (additional \%6.2 risk). In addition, in the presence of leukoaraiosis, a 1.3-fold worse prognosis (additional $15.4 \%$ absolute risk increase) and in the presence of moderate/ severe leukoaraiosis, 1.31-fold worse prognosis (additional 17.5\% risk) are observed (49). Thus, the presence of small vessel disease causes a poor prognosis by causing both increased bleeding risk and decreased recovery. Nevertheless, the results of IV tPA in such patients are still better and IV tPA should be administered (50).

Question: What is the importance of early infarction signs in cranial CT in terms of thrombolytic treatment?

Answer: Detection of early infarction signs is challenging and requires expertise. Explanations about early infarction signs were removed from the last FDA label (26). On the contrary, in the last AHA guideline, some early infarction signs were defined as encouraging for IV tPA (7). Hyperdense artery findings, blurring of the lentiform border, insular ribbon sign, cortical swelling/ increase in volume and blurred hypodensity are such signs. On the other hand, IV tPA is not beneficial and should be avoided in the presence of late infarction signs including "edema with mass effect", "shift" and "demarked large hypodense infarction".

"Hyperdense" or "dense" for short, artery findings are relatively better detected, and if detected in the proximal vasculature it helps to make the decision for mechanical thrombectomy following IV tPA. The dense artery sign in the branches of the middle cerebral artery (MCA) is called the "MCA dot sign". "Blurring of the lentiform border" sign is seen in the terminal internal carotid artery, MCA M1 or proximal M2 occlusions. The "insular ribbon" sign is seen early in proximal MCA occlusion due to distant or insufficient collaterals. Neither are contraindications for IV tPA. The most important sign of infarction is hypodensity. If the water content in brain tissue increases by $1 \%$, brightness decreases by 2.5 HU in CT and a decrease by $5 \mathrm{HU}$ can be seen by eye. Loss of Cortical grey-white matter border is an especially important finding. The extent of hypodensity is also important besides its clarity. If there is clear hypodensity, the first thing to do is to check the time of stroke. If the time data is correct, the patient should be evaluated in terms of administering IV tPA.

The extent of hypodensity is evaluated by two measurements. First is the ECASS criterion (9). This criterion includes hypodensity in more than $1 / 3$ of the MCA territory, which is related with lower benefit and higher bleeding risk following IV tPA. If ECASS-1 is positive, the odds ratio of good prognosis is $0.41[95 \% \mathrm{CI}$ : (0.06-2.70)], whereas it is 3.43 [95\% CI: (1.61-7.33)] if ECASS-1 is negative. Accordingly, if the criterion is positive, tPA is not effective, and if it is negative, tPA is effective (51). However, this post hoc result could not be replicated in ECASS-2. In addition, it could not be replicated in the NINDS study, which had positive results (ECASS-2 had negative results) (52). Therefore, this criterion should not be used to avoid IV tPA. This criterion is not found in many user manuals, including ours. "Severity of stroke shown by appropriate imaging methods..." is written in our user manual, which is not met by ECASS criterion (20).

Another criterion is the "Alberta Stroke Program Early CT Score" (ASPECTS) system, which is more complex (53). In this semi-quantitative scale, MCA is divided into 10 parts based on potential functional roles. Although the internal capsula, basal ganglia, and caudate nucleus constitute a smaller area, they score equal to large hemispheric areas, which originates from this "functional roles" argument. Each of these 10 parts scores 1 point if there is no hypodensity. Healthy subjects score 10 points, whereas patients with total MCA infarctions score 0 points. In the original study, prognosis and response to tPA were found better in patients with 8-10 points compared with patients with 3-7 points. Patients with 0-2 points did not benefit from tPA; this was not replicated in the NINDS trial (54). The rate of patients who did not have ASPECTS 10 was $57 \%$ in the NINDS trial. Response to tPA was better in patients with 8-10 points compared with patients with 3-7 points (number needed to treat is 5 and 8 , respectively). However, the response to tPA was also good in patients with lower ASPECTS, which was interpreted as low clinical value. The rate of patients with $0-2$ points was $2.6 \%$ in the NINDS trial, which prevents making further decisions. Current data show hypodensity-based exclusion criteria for treating patients with IV tPA within 3 hours are not evidence-based and efficient. In the 3-4.5-hours period, the ECASS criterion that was used in the ECASS-3 trial can be considered but many authorities think it is not necessary. More data are required for patients with ASPECTS 0-2. 


\section{Question: Can IV tPA be administered in patients with unknown stroke onset time?}

Answer: IV tPA can be administered in some of these patients based on imaging data. Health authorities approved IV tPA in acute ischemic stroke in the first 3 or 4.5 hours $(7,19,20,26)$. Therefore, the onset time of stroke should be clear and between this mentioned period. If the onset time is not known exactly, the last time the patient seemed normal is accepted as the onset time of stroke. Unknown onset time constitutes $25 \%$ of causes of non-administration of IV tPA (55); half of which are "wakeup" stroke. Before discussion, it should be known that there is an impression that wake-up strokes occur near waking up (16). The similarity between the rates of BT/MR perfusion mismatch, lesion volume, and occlusion of the main arteries between patients with wake-up stroke and patients with known onset stroke support this argument (56).

For patients in whom 4.5 hours are exceeded and the starting time of stroke is not known, lytic treatment can be given based on imaging data. At this point, the important imaging findings are: no hypodensity in cranial CT; major vessel occlusion in CT angiography in a patient with normal or near normal CT; large decreased perfusion area with small hypodensity in CT and CT perfusion; smaller area with low cerebral blood flow $(<2 \mathrm{cc} / 100$ $\mathrm{g}$ or below $30 \%$ of normal) and larger area with prolonged MTT (>145\% or $\mathrm{t}_{\max } \geq+6 \mathrm{~s}$ ); if performed, smaller diffusion restriction compared with clinical score (clinic-diffusion mismatch or DAWN criterion) (57); larger area in diffusionweighted images but smaller area in fluid-attenuated inversion recovery (FLAIR) (MR-Witness criterion) (58); large area with impaired perfusion without diffusion restriction (perfusion diffusion mismatch, PDM criteria) (59). Modalities involving MR perfusion require advanced technical and organizational infrastructure. DAWN and MR-Witness criteria besides PDM are discussed in this review because it is relatively easier to use them in clinical practice. It should be noted that these suggestions of lytic treatment based on imaging are not yet included in the guidelines.

MR-Witness criterion refers to the large difference between the hyperintense area in diffusion-weighted imaging (DWI) and the hyperintense area in FLAIR. In this case, there must also be a mismatch between the FLAIR-positive area and clinical deficit. The recommended criterion is NIHSS $\geq 8$ and MRI-ASPECTS $\geq 8$ or MRI lesion volume $\leq 25$ cc (60). This phenomenon is defined in the literature as "diffusion-FLAIR mismatch" or "DWIpositive FLAIR-negative" (DPFN) stroke. Presence of this finding may indicate that the stroke developed over the last 4.5 hours. However, the sensitivity is $50 \%$ and specificity is $75 \%$, and the measured intensity does not change as time passes $(61,62)$. On the other hand, clinically predicting this MRI finding is not possible (63). Leading alone with this phenomenon toward the treatment in wake-up or unknown onset time stroke is safe to a degree at bedside but seems not efficient. However, it should be noted that performing IV tPA in the first 24 hours (mean 11.3 hours) in DPFN stroke resulted in encouraging results including a symptomatic bleeding rate of $1.5 \%$ and $44 \% \mathrm{mRS} 0-1$ at the $90^{\text {th }}$ day in the MR-Witness trial, the details of which are not known (58). Patients with NIHSS $>25$, with DWI lesions larger than $1 / 3$ of the MCA territory (modified ECASS criterion), with a DWI volume more than $100 \mathrm{cc}$ measured using the ellipsoid ABC/2 formula were excluded in the MR-Witness trial. The usefulness of this method should be shown with phase-3 trials (64).

Clinic-ischemic core (diffusion) volume mismatch was studied in the DAWN trial, which reported its positive results in 2017 (57). In this study, thrombectomy was performed in patients with clinic-core mismatch (if NIHSS was $<10$ and diffusion or $\mathrm{CBV}$ volume was $\leq 21$ cc in patients aged $\geq 80$ years, and if NIHSS $>10$ and diffusion or CBV volume were $\leq 31 \mathrm{cc}$ and if NIHSS was $>20$ and diffusion or CBV volume were $\leq 51 \mathrm{cc}$ in patients aged $<80$ years) were selected from patients with MCA or terminal ICA occlusion who woke up after 6-24 hours had passed from the last time they were seen normal. Thrombectomy in such patients resulted in 35.5\% mRS 0-2 rate at 90 days ( $48.6 \%$ in tPA group vs. $13.1 \%$ in the control group), which is a remarkable result. It is suggested that this strategy should be performed to 2 patients to result in improvement in $\mathrm{mRS}$ by at least 2 points, and it should be performed to 2.8 patients to obtain one patient with mRS 0-2 at 90 days. The DAWN criterion was found in $1 / 3$ of all patients. It should be noted that these results are extremely strong and guideline makers will take them into account. However, this positive result cannot be used for IV tPA.

Lastly, perfusion-diffusion mismatch (PMD), a method currently used that became popular to highlight "tissue time" before the 2 methods mentioned above, can be used in late arriving and wake-up stroke. If the pathologic hypoperfusion area shown by perfusion-weighted imaging is larger than the hyperintense area shown by DWI, and the area in DWI is small, then the patient's response to reperfusion will be better (target "mismatch" paradigm). For this reason, the perfusion/diffusion volume ratio should be at least 1.2 and the difference between the volumes should be at least $10 \mathrm{cc}$. But these values increase up to 2.6 and $50 \mathrm{cc}$, respectively, in the literature (59). In the Diffusion and Perfusion Imaging Evaluation For Understanding Stroke Evolution (DEFUSE) (65) and Echoplanar Imaging Thrombolytic Evaluation Trial (EPITHET) (66), preventing an increase in infarction volume in patients with target PDM did not affect outcomes in a satisfactory manner, but the results were better in patients with mismatch (67). Evaluation of automated software that allows performing the evaluation immediately can facilitate spreading this strategy. In the DEFUSE-III trial, patients who are admitted within 6-16 hours and have PDM in target BTP/BT angiography or MR-perfusion/diffusion/angiography (diffusion volume $<70 \mathrm{cc}$, "mismatch" rate $>1.8$ and "mismatch" volume $\geq 15$ cc) are being randomized.

\section{Question: Is IV tPA safe in cases of unruptured intracranial aneurysm?}

Answer: The incidence of unruptured saccular intracranial aneurysms in the community is around $2-3 \%$. That is, it is obvious that coincidental aneurysm in ischemic stroke is not rare. The incidence of coincidental aneurysms has increased due to the increasing use of CT angiography in the diagnosis and treatment planning of acute stroke, and this question has gained importance in the clinical decision-making process. 
Experience with the use of IV tPA in cases of unruptured aneurysms is based on case series. For example, there was no increase in intracerebral hemorrhage rates in a study involving the use of IV tPA for acute stroke in 22 patients with unruptured saccular aneurysms (27\% greater than $5 \mathrm{~mm}$ ). In this study, symptomatic intracerebral hemorrhage after IV tPA was not observed in patients with aneurysm and its incidence was $5 \%$ in patients without aneurysm. The diagnosis of SAH in imaging was found to be $5 \%$ in patients with aneurysms and $6 \%$ in patients without aneurysms (68). In these series, the frequency of aneurysm was between 3-9.5\% and rupture of the aneurysm after IV tPA was not reported (69), but $15 \%$ of aneurysms were greater than $5 \mathrm{~mm}$ and only $6.3 \%$ were over $10 \mathrm{~mm}$ in diameter (70). The AHA commission noted that the presence of aneurysms with a diameter less than $10 \mathrm{~mm}$ on CT angiography would not change the IV tPA decision and that larger aneurysms could not be assured of safety and more experience was needed (7). In the literature, aneurysmal rupture (mortal) after systemic tPA has been published in at least 3 non-stroke cases, one combined with heparin for AMI and a 100 -mg dose $(71,72,73)$. There is no such case report in the dose used for stroke. We believe that the presence of coincidental aneurysm does not constitute a contraindication to the use of IV tPA in patients with stroke. The answer to a different question, whether the use of IV tPA is effective or safe in thrombotic giant or fusiform aneurysms presenting with embolism or compression is not clear (74).

\section{Question: Can IV tPA be administered if there is an intracranial vascular malformation?}

Answer: The presence of intracranial untreated or newly detected arteriovenous malformation (AVM) has been described as "exclusion criterion" in the AHA guideline and "serious warning" in the FDA label. There is not enough experience in the tPA literature regarding cavernous angioma, capillary telangiectasia, developmental venous anomalies, or arteriovenous fistulas (AVF) (75). Therefore, no clear recommendations can be made for the use of IV tPA in vascular malformation cases, especially untreated AVM and AVF. The risk is probably proportional to the natural rupture risk of the malformation. For this reason, it may be advisable to evaluate the case together with Neurosurgery and Interventional Neurology such that this practice can be decided until original studies are published.

\section{Question: Is IV tPA contraindicated in stroke caused by cervical artery dissection?}

Answer: Traumatic and non-traumatic dissections of the cervical extracranial carotid artery and vertebral artery are not rare causes of stroke. In a meta-analysis of 121 patients, IV tPA administration was not associated with additional risk in the context of cervical artery dissection and was not found to have a significant effect on the prognosis of the patients (76). This finding was supported by both a meta-analysis of 234 patients and a prospective study involving 39 patients (77). Regarding this, we can say that IV tPA can be used in acute stroke due to extracranial arterial dissection (69). Dilatation of the dissection, rupture or enlargement of the aneurysm has not been reported following
IV tPA (78). However, some experts are of the opinion that IV administration is safe, but less effective, and that interventional treatment is more appropriate for extracranial dissections leading to critical stenosis causing hemodynamic impairment (78). In intracranial dissections, IV tPA should not be given for "definitively proven" intracranial dissections except within the scope of the study because the experience of use is limited to a few case reports and the risk of bleeding is already high, but if administered, one should know that there is no published case of worsening (79).

\section{Question: Can IV tPA be administered if there is a brain tumor?}

Answer: Brain tumors have been described as "contraindications" in the 2013 guidelines of the AHA and "warning" in the FDA tPA label $(7,26)$. The underlying idea may be the theoretical bleeding risk for glioblastoma multiforme (GBM). However, IV tPA has been successfully used in many cases in the literature, including those diagnosed later as GBM (80). Bleeding into the tumor was reported in a patient with GBM 20 days after IV tPA for ischemic stroke (81). Naturally, the connection between the two is unclear. In the literature, the use of IV tPA for AMI or PTE has been reported in nearly twenty patients with GBM and intra-tumoral bleeding was not observed (16). No tumoral bleeding was reported in over 30 patients with extra-axial tumors (acoustic neuroma, meningioma) who were treated with IV tPA for ischemic stroke (82). Except for special conditions, administration of IV tPA is not contraindicated in extra- or intra-axial primary brain tumors. In particular, incidental meningiomas do not pose a risk.

The risk of stroke is high in metastatic systemic cancers. In this case, the reported experience with the use of IV tPA is limited. However, IV tPA may be at risk in tumors with a high risk of hemorrhage, such as renal cell carcinoma, cholangiocarcinoma or melanoma brain metastases. Its use in these cases should be assessed on a patient basis. Further experience is needed for the use of IV tPA in cerebral/systemic embolism on the basis of tumorrelated thrombophilia (Trousseau syndrome) (83). Disseminated intravascular coagulation in these patients should be ruled out, because it may be risky for bleeding.

\section{Question: Is an intervention to the dura in the last 7 days a contraindication for IV tPA?}

Answer: Systemic thrombolytic administration after intervention of the dura mater for lumbar puncture (LP) or other purposes may lead to epidural/subdural hematoma or spinal $\mathrm{SAH}$, which is at risk of developing compressive myelopathy (84). Factors such as the disease requiring CSF withdrawal, the number of trials, and needle thickness and type are of particular interest in calculating the theoretical risk of bleeding in the intervention region. In a small number of patients with spinal bleeding in the literature, IV tPA and heparin were commonly used together. There is no spinal hemorrhage after IV tPA alone (16). Obviously, it is a very rare condition in stroke clinical practice and TPA administration in patients with stroke who underwent LP should not be considered as an absolute contraindication. 
Question: Can IV tPA be administered in patients who have undergone intracranial or spinal surgery in the last 3 months?

Answer: This is written as an exclusion criterion in the FDA label and the AHA guidelines $(7,26)$. It is due to the fear of hemorrhage in the surgical site. In these cases, it is generally advisable to prefer thrombectomy. In fact, there is no case study in the literature that shows this risk.

Question: Can IV tPA be administered in patients with major head trauma in the past 3 months?

Answer: "Serious" head trauma within the last 3 months has been noted as a contraindication to administer IV tPA in the FDA label. The incidence of cerebral infarction (post-traumatic stroke) in cases of head trauma is $2-10 \%$. IV tPA administration is not generally recommended in these patients with acute trauma. In these cases, coagulopathy, systemic or skull fracture, cerebral contusion, diffuse axonal injury, and traumatic intracranial hemorrhage are not rare and they pose a risk for the use of Tpa (69). It is not a well-covered subject In the literature either. Fatal intracerebral hemorrhage has been reported with IV tPA after severe head trauma in one case (85). Although there are cases of head trauma in the off-label IV tPA series, comments cannot be made because the details of these patients are not compiled separately. The use of IV tPA for stroke in hospitalized patients due to head trauma is a multidisciplinary question that should be assessed at the bedside and there is no decisive data in the literature.

Question: How does epileptic seizure at the onset of stroke symptoms affect the tPA decision?

Answer: In the original FDA use label, epileptic seizure at the onset of stroke symptoms is a contraindication, but it was listed as a "relative exclusion criterion" in the 2013 AHA guidelines (7). It has been completely removed from the current FDA label (26). There is no renewal in the Turkish instructions for use and there is the statement "presence of coincidental seizures at the onset of stroke" under the heading "it should not be used in stroke due to sudden vascular occlusion and additionally in the following situations", which is open to interpretation (20). Ultimately, this discussion may be due to its being an exclusionary criterion in the NINDS study, or it may have originated from the presumptions that post-seizure head trauma may increase the risk of hemorrhage, or that the suspected stroke may actually be post-ictal (Todd) paresis. Aphasia may also be misinterpreted as post-ictal confusion. It is not a very common occurrence that the stroke is caused by a seizure and the frequency is less than $1 \%$ (86). There is a stroke in at least half of all patients admitting to the emergency department with seizures and subsequent focal neurologic deficits. In the literature, IV tPA was safely used in 300 patients with seizures at the onset of stroke (or before IV tPA) (16). Symptomatic intracerebral hemorrhage was seen in 2 patients, one of whom had glial tumor resection. If there is no clinically clear distinction, further imaging can distinguish ischemia and epilepsy, but it is not recommended because it is time consuming and ineffective. IV tPA should be given if complete discrimination is not possible (16).

\section{Question: Can IV tPA be administered for acute stroke in a dementia patient?}

Answer: Dementia has not been written as a contraindication in the FDA, AHA, and Turkish tPA instructions for use. The prognosis of acute stroke in patients with dementia is worse than in those with normal cognition. In many studies, symptomatic bleeding and mortality rates with IV tPA in patients with dementia were reported to be similar or slightly increased compared with other patients (87). However, almost all studies have shown that functional recovery with IV tPA occurs at a lower level in patients with dementia.

\section{Question: Can IV tPA be used in a patient who cannot consent?}

Answer: Informed consent similar to pre-surgical consents should be taken prior to IV tPA because the frequency and severity of adverse effects are far from being negligible. Yet being a vital surgery analogue, the patient can reject the treatment. In this case, however, it must be ensured that patients understand what they are denying.

A relative is needed when the patient's consciousness or neurologic deficits (e.g., aphasia) interferes with treatment decision-making. The absence of relatives cannot prevent the treatment ethically and legally (16). The relative shortness of the onset of treatment necessitates the rapid implementation of consent. This also becomes a problem during decision-making. It is useful that the IV tPA consent form is very clear and contains descriptive figures. The consent process must be conducted by health personnel in all aspects. As in the case of the surgical note, a note summarizing the information and decisions of the physician about the situation is also sufficient. However, readymade forms are more practical if present. At this point, it should be noted that in many countries, "special" consent is not required to administer IV tPA in acute stroke; its efficacy is accepted as a proven treatment, it is covered in the general consent signed on admission to the hospital such as with antibiotics, and this is useful in becoming widespread.

\section{Question: What should be done if intracerebral hemorrhage occurs after IV tPA?}

Answer: Intracerebral hemorrhage and associated clinical deterioration is a rare, but most critical and feared adverse effect of IV tPA. tPA infusion should be stopped immediately and imaging (preferably CT) should be performed in the event of a new or character-changing headache, nausea, vomiting, worsening neurologic deficit or emergence of new deficits, and a blood sample should be sent rapidly for complete blood count, PT, PTT, platelets, fibrinogen, and D-dimer. If the blood pressure is high, it should be immediately taken under control.

Risk factors for post-thrombolytic cerebral hemorrhage include advanced age, massive early infarct findings in CT (often late cases), pathologically elevated blood glucose, thrombocytopenia, and 
other coagulopathies, and uncontrolled blood pressure (88). The most frequent time for tPA-related intracerebral hemorrhage is the first hours after onset of IV treatment and the average bleeding time was 470 minutes in one study (89). Only hemorrhage within the first 36 hours post-treatment can be associated with tPA (89).

In the NINDS tPA trial, "symptomatic" post-thrombolytic intracerebral hemorrhage was defined as hemorrhage not present in pre-treatment CT and temporally linked with accompanying clinical worsening at any grade (90). Regarding this definition, hemorrhage was $6.4 \%$ in the original NINDS trial (6). The ECASS trials stipulated the requirement of a minimum increase of 4 points in NIHSS for the diagnosis of clinical deterioration (88). In ECASS-3, the rule that a hemorrhage can be called symptomatic hemorrhage if the clinical worsening could be explained by the hemorrhage was added. Post- and peri-thrombolysis hemorrhages are radiologically divided into 4 categories in the ECASS system ("Fiorelli classification") (91): "Hemorrhagic transformation (HT) type-1" has solitary petechial hemorrhage at the border of the hypodense area. The hemorrhage is called "HT type-2" if the hemorrhage is united rather than solitary and punctate, and larger and within the hypodense area. If the confluent hyperdensity occupies less than $1 / 3$ of the hypodense area and has a minimal mass effect, this type of mild intra-infarct hematoma is called "parenchymal hematoma (PH) type-1". These intra-infarct hematomas are called "PH type2 " if they occupy more than $1 / 3$ of the hypodense area, are located in the ventricles, are located or spread beyond the borders of the infarct zone, or have a significant mass effect. Type- $2 \mathrm{PH}$ is almost always symptomatic and associated with poor prognosis. In the SITS trial, ECASS PH type- 2 and at least 4 NIHSS criterion points worsening were combined. Both ECASS and SITS symptomatic (or clinically significant) intracerebral hematoma criteria are more stringent than those used in the original NINDS. Hemorrhage in the NINDS study was $3.4 \%$ with the ECASS criterion and $1.9 \%$ with the SITS criterion (90). The mortality of $\mathrm{PH}$ type 2 hematomas is more than 50\% (92). Expansion and clinical deterioration in follow-up imaging modalities occur in approximately $50 \%$ of cases within the first 24 hours (89). For this reason, follow-up CT is performed with 4-6-hour intervals on the first day. In the meantime, neurosurgery consultation should be held.

Significant reductions in fibrinogen levels $(<150 \mathrm{mg} / \mathrm{dL}$ or a decrease of $200 \mathrm{mg} / \mathrm{dL}$ or more) (89) following systemic tPA are associated with post-thrombolytic intracerebral hematoma development and expansion. For this reason, treatment protocols should include antifibrinolytic and cryoprecipitate (or fibrinogen) (93). The treatment modalities and approach to thrombolyticrelated intracerebral hemorrhages vary widely (92).

The most commonly used anti-fibrinolytic agent is epsilonaminocaproic acid (EACA, Amicar ${ }^{\circledR}$ ) and it is recommended to be administered in 15 to 30 minutes in the form of IV bolus of 5 gram. EACA directly reverses tPA and inhibits the proteolytic activity of plasmin. It takes around 3 hours for its activity to reach its maximum level. In massive hemorrhages, Amicar ${ }^{\circledR}$ may also be given at higher doses (IV in 1 hour with $10 \mathrm{~g}$ in $250 \mathrm{cc}$ saline) $(92,93)$. Tranexamic acid may be substituted for this agent, which is not found in our country, but there is not enough experience. Tranexamic acid (Transamin ${ }^{\circledR}$ ) may be recommended as a loading dose of $1 \mathrm{~g} / 10 \mathrm{~min}$ IV infusion followed by a $1 \mathrm{~g}$ IV/8 h IV infusion (94).
If fibrinogen is below $100 \mathrm{mg} / \mathrm{dL}$, generally 10 units $(0.15$ units $/ \mathrm{kg}$ ) of cryoprecipitate are administered IV. If fibrinogen is still below $100 \mathrm{mg}$ after 1 hour, the cryoprecipitate dose is repeated. Cryoprecipitate is a cold precipitate of fresh plasma. It includes factor VIII (100 units in 1 unit cryoprecipitate), von Willebrand factor, and fibrinogen (200 $\mathrm{mg}$ in 1 unit cryoprecipitate). Ten units of cryoprecipitate increase fibrinogen levels by $50-70 \mathrm{mg} / \mathrm{dL}$. Providing a direct fibrinogen preparation (Haemocomplettan ${ }^{\circledR} 1$ gram vial) at this point is a good alternative. Four units of platelet solution are usually recommended because there is platelet dysfunction with tPA. However, experience with vitamin $\mathrm{K}$, fresh frozen plasma, and 4-factor combined preparation is less (95).

\section{Question: If IV tPA is to be administered between 3-4.5 hours following the onset of stroke, what additional criteria should be checked?}

Answer: IV tPA administration, along with the positive results of the ECASS-3 study in 2008, has expanded to include 3-4.5 hours. In this study, a good functional outcome [mRS 0-1: $45.2 \%$ vs. 52.4\%, OR: $1.34 ; 95 \%$ CI: (1.01-1.76)] could be ensured by IV tPA at a standard dose in 418 patients despite slight increases in hemorrhage rates (symptomatic intracerebral hemorrhage: tPA $2.4 \%$, placebo: $0.2 \%)$. There was no change in mortality rates $(7.7 \%$ to $8.4 \%)(8)$.

In this study, some additional exclusion criteria were applied in patient selection. First, it should be noted that this group of patients were milder than the patients treated within the first 3 hours. In the control group, the mean NIHSS was 11.6, the mRS $0-1$ ratio at 3 months was $45.2 \%$, and the mRS $0-2$ ratio was $62.3 \%$. This was the first additional criterion. Thus, severe stroke cases were excluded. The clinical criterion for severe stroke is NIHSS > 25 and/or wide hypodensity in CT, which includes more than one third of the possible MCA area. The second additional criterion was age $\geq 80$ years. The prominence of this criterion was mentioned above. The third criterion was the combination of stroke and diabetes mellitus, and the last criterion was being under oral anticoagulant therapy. That is, regardless of the INR value, the "current" use of warfarin is contraindicated for IV tPA between 3-4.5 hours in patients with ischemic stroke. It is advisable to check these additional criteria "generally" when tPA will be given in this time frame.

The limitation of IV tPA use within the first 3 hours in patients older than 80 years was mentioned to be unscientific at the beginning of the article. This view may also apply for IV tPA application between 3-4.5 hours. In the EPITHET and ISTIII studies, 970 patients aged over 80 years who received IV tPA between 3 and 6 hours were found to have no significant difference when compared with those younger than 80 years. However, in these groups, the efficacy of IV tPA remained marginal (96). The symptomatic hemorrhage rate in 1008 patients with stroke aged over 80 years who were registered in the Get With The Guideline (GWTG) database and who received IV tPA between 3-4.5 hours was $8 \%$ and it was not different compared with the same age group treated within the first 3 hours $(6.7 \%)$. On the other hand, the functional outcomes of those older than 80 years treated within the first 3 hours were not better than those treated between 3-4.5 hours; the rates of ambulatory patients during discharge were 
$17.7 \%$ vs. $19.5 \%$, and discharge to home were $20.3 \%$ vs. $21.2 \%$ (97). Therefore, the interval between hours 3-4.5 is not different from other time periods regarding IV tPA in older patients. In short, with IV tPA, benefit is reduced as time and age increase, but always continues.

The fact that the efficacy of tPA continues as the clinical stroke severity increases was discussed at the beginning of the article. The situation of IV tPA between 3-4.5 hours in patients with a NIHSS limit of 25 or more, which was used in ECASS-3, is not an adequately studied subject. Symptomatic intracerebral hemorrhage ( $8.4 \%$ vs. $10 \%)$, ambulatory status during discharge (7.8\% vs. $10 \%)$ and discharge to home $(11.7 \%$ vs. $11.5 \%)$ in 179 patients in the GWTG database who were treated with tPA after 3 hours were not different from patients with NIHSS >25 who were treated within the first 3 hours (97). In practice, a significant portion of patients with high NIHSS at this time cannot undergo tPA because of the large hypodensity seen in imaging after 3 hours. Those without observed hypodensity may be considered as anterior system occlusions, either with the vertebrobasillary system or with good collateral status. In both cases, it is appropriate that IV tPA is administered and if conditions are suitable, thrombectomy should be performed.

It is known whether the use of IV tPA within the first 3 hours is appropriate if there is an INR level of $<1.7$ in patients with regular oral anticoagulant use. The differences in these patients have already been addressed in this article. At this point, it should be noted that oral anticoagulants only include vitamin $\mathrm{K}$ antagonists. The use of sub-therapeutic (INR <1.7) warfarin between 3-4.5 hours was examined in 282 patients in the GWTG database and compared with those treated within the first 3 hours. Symptomatic intracerebral hemorrhage $(5.7 \%$ vs. $6.8 \%)$, ambulatory status during discharge (26.6\% vs. $24.7 \%)$ and discharge to home $(30.5 \%$ vs. $26.4 \%)$ were similar in both groups (97). Therefore, the use of IV tPA in these patients should be determined at the individual level.

IV tPA should be used when ischemic stroke develops in patients with diabetes. IV tPA is used within the first 3 hours in the event of recurrence in patients with diabetes who have already had a stroke. Although the efficacy of tPA in these patients is on the positive side, it decreases. In fact, it would be useful to use IV tPA for 3-4.5 hours with the same reasoning, but this was an exclusionary criterion in ECASS-3. In many series on diabetics with ischemic stroke recurrence, no negativity was found regarding mortality, symptomatic intracerebral hemorrhage, and functional outcomes with IV tPA $(41,98)$. In fact, in VISTA, a good functional outcome rate was found that tended to be higher in diabetics with a prior stroke $(\mathrm{n}=86)$ than in diabetics without a prior stroke $(n=405)(O R=1.5)(98)$. In an analysis of 335 patients with diabetes in the GWTG database who had stroke recurrence and were treated between $3-4.5$ hours, the rates of symptomatic intracerebral hemorrhage $(6.9 \%$ vs. $4.6 \%)$, ambulatory status during discharge $(34.9 \%$ vs. $30.8 \%)$, and discharge to home ( $40.3 \%$ vs. $36.9 \%)$ were similar to patients with diabetes with prior stroke who were treated within the first 3 hours (97). That is, the data to exclude these patients is not more convincing than the data not to.

In our country, among the additional exclusion criteria for the use of tPA between 3-4.5 hours, which are;
1- Age over 80 years,

2- Oral anticoagulant use irrespective of INR value,

3- Pre-treatment NIHSS $>25$,

4- Wide hypodense area in one third of the possible MCA field in $\mathrm{CT}$, and

5- A combination of diabetes and stroke, criteria 1 (age), 3 (NIHSS) and 5 (diabetes and prior stroke) are written in the form of generalized instructions to all patients (20).

On the other hand, the FDA has not yet approved IV tPA in this period $(26,99)$. It is therefore appropriate that the decision for the use of IV tPA should be made according to individual circumstances in a rational clinical approach, and it should not be considered as a definitive contraindication.

\section{Ethics}

Peer-review: Externally peer-reviewed.

\section{Authorship Contributions}

Concept: M.A.T., E.M.A., A.Ö.Ö., E.G., D.N.Ö., Ş.Ö., Design: M.A.T., E.M.A., A.Ö.Ö., E.G., D.N.Ö., Ş.Ö., Data Collection or Processing: M.A.T., E.M.A., A.Ö.Ö., E.G., D.N.Ö., Ş.Ö., Analysis or Interpretation: M.A.T., E.M.A., A.Ö.Ö., E.G., D.N.Ö., Ş.Ö., Literature Search: M.A.T., E.M.A., A.Ö.Ö., E.G., D.N.Ö., Ş.Ö., Writing: M.A.T., E.M.A., A.Ö.Ö., E.G., D.N.Ö., Ş.Ö.

Conflict of Interest: All authors have taken part in Scientific Advisory Board of Boehringer Ingelheim Turkey on tPA usage in stroke.

Financial Disclosure: The authors declared that this study received no financial support.

\section{References}

1. De Brun A, Flynn D, Joyce K, Ternent L, Price C, Rodgers H, Ford GA, Lancsar E, Rudd M, Thomson RG. Understanding clinicians' decisions to offer intravenous thrombolytic treatment to patients with acute ischaemic stroke: a protocol for a discrete choice experiment. BMJ Open 2014; 4:e005612.

2. Messe SR, Khatri P, Reeves MJ, Smith EE, Saver JL, Bhatt DL, GrauSepulveda MV, Cox M, Peterson ED, Fonarow GC, Schwamm LH. Why are acute ischemic stroke patients not receiving IV tPA? Results from a national registry. Neurology 2016;87:1565-1574.

3. Nasr DM, Brinjikji W, Cloft HJ, Rabinstein AA. Utilization of intravenous thrombolysis is increasing in the United States. Int J Stroke 2013;8:681-688.

4. Topcuoglu MA, Cekirge HS, Saribas O. Akut iskemik inmede trombolitik tedavi. Turk J Neurol 1997;3:111-119.

5. Kutluk K. Akut iskemik inmede intravenöz trombolitik tedavi Sorumluluğumuzun farkında mıyız? Türk Serebrovasküler Hastalıklar Dergisi 2009;15:35-39.

6. National Institute of Neurological Disorders and Stroke rt-PA Stroke Study Group. Tissue plasminogen activator for acute ischemic stroke. N Engl J Med 1995;333:1581-1587.

7. Jauch EC, Saver JL, Adams HP Jr, Bruno A, Connors JJ, Demaerschalk BM, Khatri P, McMullan PW Jr, Qureshi AI, Rosenfield K, Scott PA, Summers DR, Wang DZ, Wintermark M, Yonas H; American Heart Association Stroke Council; Council on Cardiovascular Nursing; Council on Peripheral Vascular Disease; Council on Clinical Cardiology. Guidelines for the early management of patients with acute ischemic stroke: a guideline for healthcare professionals from the American Heart Association/American Stroke Association. Stroke 2013;44:870-947.

8. Hacke W, Kaste M, Bluhmki E, Brozman M, Dávalos A, Guidetti D, Larrue V, Lees KR, Medeghri Z, Machnig T, Schneider D, von Kummer R, Wahlgren N, Toni D; ECASS Investigators. Thrombolysis with alteplase 3 to 4.5 hours after acute ischemic stroke. N Engl J Med 2008;359:13171329. 
9. Hacke W, Kaste M, Fieschi C, Toni D, Lesaffre E, von Kummer R, Boysen G Bluhmki E, Höxter G, Mahagne MH, et al. Intravenous thrombolysis with recombinant tissue plasminogen activator for acute hemispheric stroke. The European Cooperative Acute Stroke Study (ECASS). JAMA 1995;274:10171025 .

10. Hacke W, Kaste M, Fieschi C, von Kummer R, Davalos A, Meier D, Larrue V, Bluhmki E, Davis S, Donnan G, Schneider D, Diez-Tejedor E, Trouillas P. Randomised double-blind placebo-controlled trial of thrombolytic therapy with intravenous alteplase in acute ischaemic stroke (ECASS II). Second European-Australasian Acute Stroke Study Investigators. Lancet 1998;352:1245-1251

11. Baatiema L, Otim ME, Mnatzaganian G, de-Graft Aikins A, Coombes J, Somerset S. Health professionals' views on the barriers and enablers to evidence-based practice for acute stroke care: a systematic review. Implement Sci 2017;12:74.

12. Demaerschalk BM. Alteplase Treatment in Acute Stroke: Incorporating Food and Drug Administration Prescribing Information into Existing Acute Stroke Management Guide. Curr Atheroscler Rep 2016;18:53.

13. Frank B, Grotta JC, Alexandrov AV, Bluhmki E, Lyden P, Meretoja A, Mishra NK, Shuaib A, Wahlgren NG, Weimar C, Lees KR; VISTA Collaborators. Thrombolysis in stroke despite contraindications or warnings? Stroke 2013;44:727-733

14. Emberson J, Lees KR, Lyden P, Blackwell L, Albers G, Bluhmki E, Brott T, Cohen G, Davis S, Donnan G, Grotta J, Howard G, Kaste M, Koga M, von Kummer R, Lansberg M, Lindley RI, Murray G, Olivot JM, Parsons M, Tilley B, Toni D, Toyoda K, Wahlgren N, Wardlaw J, Whiteley W, del Zoppo GJ, Baigent C, Sandercock P, Hacke W; Stroke Thrombolysis Trialists' Collaborative Group. Effect of treatment delay, age, and stroke severity on the effects of intravenous thrombolysis with alteplase for acute ischaemic stroke: a meta-analysis of individual patient data from randomised trials. Lancet 2014;384:1929-1935.

15. IST-3 collaborative group, Sandercock P, Wardlaw JM, Lindley RI, Dennis M, Cohen G, Murray G, Innes K, Venables G, Czlonkowska A, Kobayashi A, Ricci S, Murray V, Berge E, Slot KB, Hankey GJ, Correia M, Peeters A, Matz K, Lyrer P, Gubitz G, Phillips SJ, Arauz A. The benefits and harms of intravenous thrombolysis with recombinant tissue plasminogen activator within $6 \mathrm{~h}$ of acute ischaemic stroke (the third international stroke trial [IST-3]): a randomised controlled trial. Lancet 2012;379:2352-2363.

16. Demaerschalk BM, Kleindorfer DO, Adeoye OM, Demchuk AM, Fugate JE, Grotta JC, Khalessi AA, Levy EI, Palesch YY, Prabhakaran S, Saposnik G, Saver JL, Smith EE; American Heart Association Stroke Council and Council on Epidemiology and Prevention. Scientific Rationale for the Inclusion and Exclusion Criteria for Intravenous Alteplase in Acute Ischemic Stroke: A Statement for Healthcare Professionals From the American Heart Association/American Stroke Association. Stroke 2016; $47: 581-641$.

17. Khatri P, Kleindorfer DO, Yeatts SD, Saver JL, Levine SR, Lyden PD, Moomaw CJ, Palesch YY, Jauch EC, Broderick JP. Strokes with minor symptoms: an exploratory analysis of the National Institute of Neurological Disorders and Stroke recombinant tissue plasminogen activator trials. Stroke 2010;41:2581-2586.

18. National Institute of Neurological Disorders Stroke rt-PA Stroke Study Group. Recombinant tissue plasminogen activator for minor strokes: the National Institute of Neurological Disorders and Stroke rt-PA Stroke Study experience. Ann Emerg Med 2005;46:243-252.

19. Casaubon LK, Boulanger JM, Blacquiere D, Boucher S, Brown K, Goddard T, Gordon J, Horton M, Lalonde J, LaRivière C, Lavoie P, Leslie P, McNeill J, Menon BK, Moses B, Penn M, Perry J, Snieder E, Tymianski D, Foley N, Smith EE, Gubitz G, Hill MD, Glasser E, Lindsay P; Heart and Stroke Foundation of Canada Canadian Stroke Best Practices Advisory Committee. Canadian Stroke Best Practice Recommendations: Hyperacute Stroke Care Guidelines, Update 2015. Int J Stroke 2015;10:924-940.

20. TCSB. ACTILYSE $50 \mathrm{mg} 1$ flakon Kullanma Talimatı PDF Dosyası. Erişim adresi: http://wwwilacrehbericom/pdfs/actilyse-50-mg-1-flakon-870d/ kt/ 2012; Erişim tarihi: 21/4/2017 (Boehringer Ingelheim İlaç Tic.A.Ş. Güncelleme: 7 September 2012).

21. Romano JG, Smith EE, Liang L, Gardener H, Camp S, Shuey L, Cook A, Campo-Bustillo I, Khatri P, Bhatt DL, Fonarow GC, Sacco RL, Schwamm
LH. Outcomes in mild acute ischemic stroke treated with intravenous thrombolysis: a retrospective analysis of the Get With the Guidelines-Stroke registry. JAMA Neurol 2015;72:423-431.

22. Re-examining Acute Eligibility for Thrombolysis Task F, Levine SR, Khatri P, Broderick JP, Grotta JC, Kasner SE, Kim D, Meyer BC, Panagos P, Romano J, Scott P; NINDS rt-PA Stroke Trial Investigators. Review, historical context, and clarifications of the NINDS rt-PA stroke trials exclusion criteria: Part 1: rapidly improving stroke symptoms. Stroke 2013;44:2500-2505.

23. Strbian D, Sairanen T, Rantanen K, Piironen K, Atula S, Tatlisumak T, Soinne L; Helsinki Stroke Thrombolysis Registry Group. Characteristics and outcome of ischemic stroke patients who are free of symptoms at 24 hours following thrombolysis. Cerebrovasc Dis 2011;31:37-42.

24. Machumpurath B, Davis SM, Yan B. Rapid neurological recovery after intravenous tissue plasminogen activator in stroke: prognostic factors and outcome. Cerebrovasc Dis 2011;31:278-283.

25. Blinzler C, Breuer L, Huttner HB, Schellinger PD, Schwab S, Köhrmann M. Characteristics and outcome of patients with early complete neurological recovery after thrombolysis for acute ischemic stroke. Cerebrovasc Dis 2011;31:185-190.

26. FDA. ACTIVASE (alteplase) for injection, for intravenous use. HIGHLIGHTS OF PRESCRIBING INFORMATION. Application 103172 This document contains: Label for ACTIVASE. Supplement 5203, Available date: 02/13/2015. Accessed on: 04/20/2017. Available from: https:/www. accessdata.fda.gov/drugsatfda_docs/label/2015/103172s5203lbl.pdf

27. Georgiadis D, Engelter S, Tettenborn B, Hungerbühler H, Luethy R, Müller F, Arnold M, Giambarba C, Baumann CR, von Büdingen HC, Lyrer P, Baumgartner RW. Early recurrent ischemic stroke in stroke patients undergoing intravenous thrombolysis. Circulation 2006;114:237-241.

28. Yalcin-Cakmakli G, Akpinar E, Topcuoglu MA, Dalkara T. Right internal carotid artery occlusion during intravenous thrombolysis for left middle cerebral artery occlusion. J Stroke Cerebrovasc Dis 2009;18:74-77.

29. Cappellari M, Tomelleri G, Carletti M, Bovi P, Moretto G. Intravenous thrombolysis on early recurrent cardioembolic stroke: 'Dr Jekyll' or 'Mr Hyde'? Blood Coagul Fibrinolysis 2012;23:78-81.

30. Qureshi AI, Malik AA, Freese M, Thompson MJ, Khan AA, Suri MF Readministration of intravenous alteplase in acute ischemic stroke patients: case series and systematic review. Am J Emerg Med 2015;33:307.

31. Brigo F, Bovi T, Tomelleri G, Bovi P, Moretto G. Repeated systemic thrombolysis after early recurrent stroke: always hazardous? Can J Neurol Sci 2012;39:114-116.

32. Sposato LA, Salutto V, Beratti DE, Monti P, Riccio PM, Mazia C. Adverse outcome of early recurrent ischemic stroke secondary to atrial fibrillation after repeated systemic thrombolysis. Case Rep Vasc Med 2013;2013:371642.

33. Alonso de Lecinana M, Fuentes B, Masjuan J, Simal P, Díaz-Otero F, Reig G, Díez-Tejedor E, Gil-Nuñez A, Vivancos J, Egido JA. Thrombolytic therapy for acute ischemic stroke after recent transient ischemic attack. Int J Stroke 2012;7:213-218.

34. Sobolewski P, Brola W, Wiszniewska M, Szczuchniak W, Fudala M, Domagalski M, Sledzińska-Dźwigał M. Intravenous thrombolysis with rt-PA for acute ischemic stroke within $24 \mathrm{~h}$ of a transient ischemic attack. J Neurol Sci 2014;340:44-49.

35. McKinney JS, Masjuan J, Purroy F, Calvet D, Ay H, Cucchiara BL. Safety of thrombolytic therapy for acute ischemic stroke after recent transient ischemic attack. J Stroke Cerebrovasc Dis 2012;21:551-554.

36. Tsivgoulis G, Sharma VK, Mikulik R, Krogias C, Haršány M, Bavarsad Shahripour R, Athanasiadis D, Teoh HL, Piperidou C, Alexandrov AV. Intravenous thrombolysis for acute ischemic stroke occurring during hospitalization for transient ischemic attack. Int J Stroke 2014;9:413-418.

37. Arsava EM, Topcuoglu MA. De-novo thrombolysis for recurrent stroke in a patient with prior history of thrombolysis. Blood Coagul Fibrinolysis 2010;21:605-607.

38. Matosevic B, Knoflach M, Werner P, Pechlaner R, Zangerle A, Ruecker M, Kirchmayr M, Willeit J, Kiechl S. Fibrinogen degradation coagulopathy and bleeding complications after stroke thrombolysis. Neurology 2013;80:12161224.

39. Lee VH, Conners JJ, Cutting S, Song SY, Bernstein RA, Prabhakaran S. Elevated international normalized ratio as a manifestation of postthrombolytic coagulopathy in acute ischemic stroke. J Stroke Cerebrovasc Dis 2014;23:2139-2144. 
40. Kvistad CE, Logallo N, Thomassen L, Waje-Andreassen U, Brogger J, Naess H. Safety of off-label stroke treatment with tissue plasminogen activator. Acta Neurol Scand 2013;128:48-53.

41. Meretoja A, Putaala J, Tatlisumak T, Atula S, Artto V, Curtze S, Häppölä O, Lindsberg PJ, Mustanoja S, Piironen K, Pitkäniemi J, Rantanen K, Sairanen T, Salonen O, Silvennoinen H, Soinne L, Strbian D, Tiainen M, Kaste M. Off-label thrombolysis is not associated with poor outcome in patients with stroke. Stroke 2010;41:1450-1458.

42. Turc G, Sallem A, Moulin S, Tisserand M, Machet A, Edjlali M, Baron JC, Leclerc X, Leys D, Mas JL, Cordonnier C, Oppenheim C. Microbleed Status and 3-Month Outcome After Intravenous Thrombolysis in 717 Patients With Acute Ischemic Stroke. Stroke 2015;46:2458-2463.

43. Tsivgoulis G, Zand R, Katsanos AH, Turc G, Nolte CH, Jung S, Cordonnier C, Fiebach JB, Scheitz JF, Klinger-Gratz PP, Oppenheim C, Goyal N, Safouris A, Mattle HP, Alexandrov AW, Schellinger PD, Alexandrov AV. Risk of Symptomatic Intracerebral Hemorrhage After Intravenous Thrombolysis in Patients With Acute Ischemic Stroke and High Cerebral Microbleed Burden: A Meta-analysis. JAMA Neurol 2016;73:675-683.

44. Wang S, Lv Y, Zheng X, Qiu J, Chen HS. The impact of cerebral microbleeds on intracerebral hemorrhage and poor functional outcome of acute ischemic stroke patients treated with intravenous thrombolysis: a systematic review and meta-analysis. J Neurol 201-;264:1309-1319.

45. Charidimou A, Shoamanesh A; International META-MICROBLEEDS Initiative. Clinical relevance of microbleeds in acute stroke thrombolysis: Comprehensive meta-analysis. Neurology 2016;87:1534-1541.

46. Zand R, Tsivgoulis G, Singh M, McCormack M, Goyal N, Ishfaq MF, Shahripour RB, Nearing K, Elijovich L, Alexandrov AW, Liebeskind DS, Alexandrov AV. Cerebral Microbleeds and Risk of Intracerebral Hemorrhage Post Intravenous Thrombolysis. J Stroke Cerebrovasc Dis 2017;26:538-544.

47. Dannenberg S, Scheitz JF, Rozanski M, Erdur H, Brunecker P, Werring DJ, Fiebach JB, Nolte CH. Number of cerebral microbleeds and risk of intracerebral hemorrhage after intravenous thrombolysis. Stroke 2014; 45:2900-2905.

48. Nighoghossian N, Abbas F, Cho TH, Geraldo AF, Cottaz V, Janecek E, Mechtouff L, Bischoff M, El Khoury C, Schott AM, Derex L, Hermier M, Tisserand LG, Amelie R, Chamard L, Berthezene Y. Impact of leukoaraiosis on parenchymal hemorrhage in elderly patients treated with thrombolysis. Neuroradiology 2016;58:961-967.

49. Kongbunkiat K, Wilson D, Kasemsap N, Tiamkao S, Jichi F, Palumbo V, Hill MD, Buchan AM, Jung S, Mattle HP, Henninger N, Werring DJ. Leukoaraiosis, intracerebral hemorrhage, and functional outcome after acute stroke thrombolysis. Neurology 2017;88:638-645.

50. Pantoni L, Fierini F, Poggesi A. Thrombolysis in acute stroke patients with cerebral small vessel disease. Cerebrovasc Dis 2014;37:5-13.

51. von Kummer R, Allen KL, Holle R, Bozzao L, Bastianello S, Manelfe C, Bluhmki E, Ringleb P, Meier DH, Hacke W. Acute stroke: usefulness of early CT findings before thrombolytic therapy. Radiology 1997;205:327-333.

52. Patel SC, Levine SR, Tilley BC, Grotta JC, Lu M, Frankel M, Haley EC Jr, Brott TG, Broderick JP, Horowitz S, Lyden PD, Lewandowski CA, Marler JR, Welch KM; National Institute of Neurological Disorders and Stroke rt-PA Stroke Study Group. Lack of clinical significance of early ischemic changes on computed tomography in acute stroke. JAMA 2001;286:28302838.

53. Barber PA, Demchuk AM, Zhang J, Buchan AM. Validity and reliability of a quantitative computed tomography score in predicting outcome of hyperacute stroke before thrombolytic therapy. ASPECTS Study Group. Alberta Stroke Programme Early CT Score. Lancet 2000;355:1670-1674.

54. Demchuk AM, Hill MD, Barber PA, Silver B, Patel SC, Levine SR; NINDS rtPA Stroke Study Group, NIH. Importance of early ischemic computed tomography changes using ASPECTS in NINDS rtPA Stroke Study. Stroke 2005;36:2110-2115.

55. Barber PA, Zhang J, Demchuk AM, Hill MD, Buchan AM. Why are stroke patients excluded from TPA therapy? An analysis of patient eligibility. Neurology 2001;56:1015-1020.

56. Silva GS, Lima FO, Camargo EC, Smith WS, Singhal AB, Greer DM, Ay H, Lev MH, Harris GJ, Halpern EF, Sonni S, Koroshetz W, Furie KL. Wake-up stroke: clinical and neuroimaging characteristics. Cerebrovasc Dis 2010;29:336-342.
57. Hughes S. DAWN: Thrombectomy Effective Up to 24 Hours After Stroke. 2017. http://www.medscape.com/viewarticle/880144\#vp_1.

58. Jeffrey S. MR WITNESS: Thrombolysis for 'Wake-Up' Stroke Safe, Feasible. also have a look at https://clinicaltrials.gov/ct2/show/NCT01282242. 03/03/2016. Accessed on: 06/26/2017. Available from: http://www. medscape.com/viewarticle/859844

59. Chen F, Ni YC. Magnetic resonance diffusion-perfusion mismatch in acute ischemic stroke: An update. World J Radiol 2012;4:63-74.

60. Tei H, Uchiyama S, Usui T. Clinical-diffusion mismatch defined by NIHSS and ASPECTS in non-lacunar anterior circulation infarction. $J$ Neurol 2007;254:340-346.

61. Ebinger M, Galinovic I, Rozanski M, Brunecker P, Endres M, Fiebach JB. Fluid-attenuated inversion recovery evolution within 12 hours from stroke onset: a reliable tissue clock? Stroke 2010;41:250-255.

62. Thomalla G, Cheng B, Ebinger M, Hao Q, Tourdias T, Wu O, Kim JS, Breuer L, Singer OC, Warach S, Christensen S, Treszl A, Forkert ND, Galinovic I, Rosenkranz M, Engelhorn T, Köhrmann M, Endres M, Kang DW, Dousset V, Sorensen AG, Liebeskind DS, Fiebach JB, Fiehler J, Gerloff C; STIR and VISTA Imaging Investigators. DWI-FLAIR mismatch for the identification of patients with acute ischaemic stroke within $4.5 \mathrm{~h}$ of symptom onset (PRE-FLAIR): a multicentre observational study. Lancet Neurol 2011;10:978-986.

63. Thomalla G, Boutitie F, Fiebach JB, Simonsen CZ, Pedraza S, Lemmens R, Nighoghossian N, Roy P, Muir KW, Ebinger M, Ford I, Cheng B, Galinovic I, Cho TH, Puig J, Thijs V, Endres M, Fiehler J, Gerloff C. Clinical characteristics of unknown symptom onset stroke patients with and without diffusion-weighted imaging and fluid-attenuated inversion recovery mismatch. Int J Stroke 2017;1747493017706245.

64. Thomalla G, Boutitie F, Fiebach JB, Simonsen CZ, Nighoghossian N, Pedraza S, Lemmens R, Roy P, Muir KW, Ebinger M, Ford I, Cheng B, Galinovic I, Cho TH, Puig J, Thijs V, Endres M, Fiehler J, Gerloff C; WAKEUP Investigators. Stroke With Unknown Time of Symptom Onset: Baseline Clinical and Magnetic Resonance Imaging Data of the First Thousand Patients in WAKE-UP (Efficacy and Safety of MRI-Based Thrombolysis in Wake-Up Stroke: A Randomized, Doubleblind, Placebo-Controlled Trial). Stroke 2017;48:770-773.

65. Albers GW, Thijs VN, Wechsler L, Kemp S, Schlaug G, Skalabrin E, Bammer R, Kakuda W, Lansberg MG, Shuaib A, Coplin W, Hamilton S, Moseley M, Marks MP; DEFUSE Investigators. Magnetic resonance imaging profiles predict clinical response to early reperfusion: the diffusion and perfusion imaging evaluation for understanding stroke evolution (DEFUSE) study. Ann Neurol 2006;60:508-517.

66. Davis SM, Donnan GA, Parsons MW, Levi C, Butcher KS, Peeters A, Barber PA, Bladin C, De Silva DA, Byrnes G, Chalk JB, Fink JN, Kimber TE, Schultz D, Hand PJ, Frayne J, Hankey G, Muir K, Gerraty R, Tress BM, Desmond PM; EPITHET investigators. Effects of alteplase beyond $3 \mathrm{~h}$ after stroke in the Echoplanar Imaging Thrombolytic Evaluation Trial (EPITHET): a placebo-controlled randomised trial. Lancet Neurol 2008;7:299-309.

67. Nagakane Y, Christensen S, Brekenfeld C, Ma H, Churilov L, Parsons MW, Levi CR, Butcher KS, Peeters A, Barber PA, Bladin CF, De Silva DA, Fink J, Kimber TE, Schultz DW, Muir KW, Tress BM, Desmond PM, Davis SM, Donnan GA; EPITHET Investigators. EPITHET: Positive Result After Reanalysis Using Baseline Diffusion-Weighted Imaging/Perfusion-Weighted Imaging Co-Registration. Stroke 2011;42:59-64.

68. Edwards NJ, Kamel H, Josephson SA. The safety of intravenous thrombolysis for ischemic stroke in patients with pre-existing cerebral aneurysms: a case series and review of the literature. Stroke 2012;43:412416.

69. Fugate JE, Rabinstein AA. Absolute and Relative Contraindications to IV rt-PA for Acute Ischemic Stroke. Neurohospitalist 2015;5:110-121.

70. Goyal N, Tsivgoulis G, Zand R, Sharma VK, Barlinn K, Male S, Katsanos AH, Bodechtel U, Iftikhar S, Arthur A, Elijovich L, Alexandrov AW, Alexandrov AV. Systemic thrombolysis in acute ischemic stroke patients with unruptured intracranial aneurysms. Neurology 2015;85:1452-1458.

71. Haji F, van Adel B, Avery M, Megyesi J, Young GB. Intracranial aneurysm rupture following intravenous thrombolysis for stroke. Can J Neurol Sci 2014;41:95-98 
72. Lagares A, Gomez PA, Lobato RD, Alen JF, Campollo J, Benito-Leon J Cerebral aneurysm rupture after r-TPA thrombolysis for acute myocardial infarction. Surg Neurol 1999;52:623-626.

73. Rammos SK, Neils DM, Fraser K, Klopfenstein JD. Anterior communicating artery aneurysm rupture after intravenous thrombolysis for acute middle cerebral artery thromboembolism: case report. Neurosurgery 2012;70:16031607.

74. Xu M, Yan SQ, Cao J, Lou M. No hemorrhagic transformation after intravenous thrombolysis in a pontine infarction patient with basilar aneurysm. CNS Neurosci Ther 2014;20:473-475.

75. Katz BS, Flemming KD. Successful IV thrombolysis followed by mechanical thrombectomy in a patient with cerebral ischemia and a dural AV fistula. Am J Emerg Med 2013;31:637.

76. Zinkstok SM, Vergouwen MD, Engelter ST, Lyrer PA, Bonati LH, Arnold M, Mattle HP, Fischer U, Sarikaya H, Baumgartner RW, Georgiadis D, Odier C, Michel P, Putaala J, Griebe M, Wahlgren N, Ahmed N, van Geloven N, de Haan RJ, Nederkoorn PJ. Safety and functional outcome of thrombolysis in dissection-related ischemic stroke: a meta-analysis of individual patient data. Stroke 2011;42:2515-2520.

77. Tsivgoulis G, Zand R, Katsanos AH, Sharma VK, Goyal N, Krogias C, Safouris A, Vadikolias K, Voumvourakis K, Alexandrov AW, Malkoff MD, Alexandrov AV. Safety and outcomes of intravenous thrombolysis in dissection-related ischemic stroke: an international multicenter study and comprehensive metaanalysis of reported case series. J Neurol 2015;262:2135-2143.

78. Engelter ST, Dallongeville J, Kloss M, Metso TM, Leys D, Brandt T, Samson Y, Caso V, Pezzini A, Sessa M, Beretta S, Debette S, Grond-Ginsbach C, Metso AJ, Thijs V, Lamy C, Medeiros E, Martin JJ, Bersano A, Tatlisumak T, Touzé E, Lyrer PA; Cervical Artery Dissection and Ischaemic Stroke Patients-Study Group. Thrombolysis in cervical artery dissection--data from the Cervical Artery Dissection and Ischaemic Stroke Patients (CADISP) database. Eur J Neurol 2012;19:1199-1206.

79. Doijiri R, Yokota C, Suzuki R, Toyoda K, Minematsu K. Intravenous recombinant tissue plasminogen activator thrombolysis in acute ischemic stroke due to middle cerebral artery dissection. J Stroke Cerebrovasc Dis 2012;21:915.

80. Garcia AM, Egido JA, Garcia ME, Simal P. Thrombolysis for ischaemic stroke and glioblastoma multiforme: a case report. BMJ Case Rep 2009;2009.

81. Grimm SA, DeAngelis LM. Intratumoral hemorrhage after thrombolysis in a patient with glioblastoma multiforme. Neurology 2007;69:936.

82. Neil W, Ovbiagele B. Intravenous thrombolysis in ischemic stroke patients with intracranial neoplasms: two cases and a literature review. Case Rep Med 2011;2011:503758.

83. Ikeda H, Enatsu R, Yamana N, Nishimura M, Saiki M. Multiple extraischemic hemorrhages following intravenous thrombolysis in a patient with Trousseau syndrome: case study. Springerplus 2015;4:141.

84. Schmidley JW, Mallenbaum S, Broyles K. Spinal epidural hematoma: an important stroke mimic. Acute Med 2013;12:30-33.

85. Lopez-Yunez AM, Bruno A, Williams LS, Yilmaz E, Zurru C, Biller J. Protocol violations in community-based rTPA stroke treatment are associated with symptomatic intracerebral hemorrhage. Stroke 2001;32:12-16.
86. Alvarez V, Rossetti AO, Papavasileiou V, Michel P. Acute seizures in acute ischemic stroke: does thrombolysis have a role to play? J Neurol 2013;260:5561.

87. Saposnik G, Kapral MK, Cote R, Rochon PA, Wang J, Raptis S, Mamdani M, Black SE. Is pre-existing dementia an independent predictor of outcome after stroke? A propensity score-matched analysis. J Neurol 2012;259:2366-2375.

88. Seet RC, Rabinstein AA. Symptomatic intracranial hemorrhage following intravenous thrombolysis for acute ischemic stroke: a critical review of case definitions. Cerebrovasc Dis 2012;34:106-114.

89. Yaghi S, Boehme AK, Dibu J, Leon Guerrero CR, Ali S, Martin-Schild S, Sands KA, Noorian AR, Blum CA, Chaudhary S, Schwamm LH, Liebeskind DS, Marshall RS, Willey JZ. Treatment and Outcome of ThrombolysisRelated Hemorrhage: A Multicenter Retrospective Study. JAMA Neurol 2015;72:1451-1457.

90. Rao NM, Levine SR, Gornbein JA, Saver JL. Defining clinically relevant cerebral hemorrhage after thrombolytic therapy for stroke: analysis of the National Institute of Neurological Disorders and Stroke tissue-type plasminogen activator trials. Stroke 2014;45:2728-2733.

91. Fiorelli M, Bastianello S, von Kummer R, del Zoppo GJ, Larrue V, Lesaffre E, Ringleb AP, Lorenzano S, Manelfe C, Bozzao L. Hemorrhagic transformation within 36 hours of a cerebral infarct: relationships with early clinical deterioration and 3-month outcome in the European Cooperative Acute Stroke Study I (ECASS I) cohort. Stroke 1999;30:2280-2284.

92. Goldstein JN, Marrero M, Masrur S, Pervez M, Barrocas AM, Abdullah A, Oleinik A, Rosand J, Smith EE, Dzik WH, Schwamm LH. Management of thrombolysis-associated symptomatic intracerebral hemorrhage. Arch Neurol 2010;67:965-969.

93. StrokeM.GuidelinesforEmergency Management of Intracerebral Hemorrhage. 2017. http://stopstroke.massgeneral.org/protocolAdultHemorrhage.aspx.

94. French KF, White J, Hoesch RE. Treatment of intracerebral hemorrhage with tranexamic acid after thrombolysis with tissue plasminogen activator. Neurocrit Care 2012;17:107-111.

95. Yaghi S, Eisenberger A, Willey JZ. Symptomatic intracerebral hemorrhage in acute ischemic stroke after thrombolysis with intravenous recombinant tissue plasminogen activator: a review of natural history and treatment. JAMA Neurol 2014;71:1181-1185.

96. Wardlaw JM, Murray V, Berge E, del Zoppo G, Sandercock P, Lindley RL, Cohen G. Recombinant tissue plasminogen activator for acute ischaemic stroke: an updated systematic review and meta-analysis. Lancet 2012;379:2364-2372.

97. Cronin CA, Sheth KN, Zhao X, Messé SR, Olson DM, Hernandez AF, Bhatt DL, Schwamm LH, Smith EE. Adherence to Third European Cooperative Acute Stroke Study 3- to 4.5-hour exclusions and association with outcome: data from Get with the Guidelines-Stroke. Stroke 2014;45:2745-2749.

98. Mishra NK, Davis SM, Kaste M, Lees KR; VISTA Collaboration. Comparison of outcomes following thrombolytic therapy among patients with prior stroke and diabetes in the Virtual International Stroke Trials Archive (VISTA). Diabetes Care 2010;33:2531-2537.

99. Cheng NT, Kim AS. Intravenous Thrombolysis for Acute Ischemic Stroke Within 3 Hours Versus Between 3 and 4.5 Hours of Symptom Onset. Neurohospitalist 2015;5:101-109. 